\title{
The Tourism Development of Ethnic Cultural Resources in Henan Province under the Background of "the Belt and Road"
}

\author{
Lingchong Jia \\ Zhengzhou University of Industrial Technology, Xinzheng, Henan, 451100 \\ Email:nn0318@foxmail.com
}

Keywords: the Belt and Road; Henan; Ethnic Culture; Tourism Development

\begin{abstract}
There are nearly 1.4 million ethnic minority populations in Henan Province, and the Hui population is second only to Ningxia and Gansu, ranking third in the country. Among the countries along the "the Belt and Road," six countries in Central Asia, 20 Arab countries in the Middle East and North Africa, and 10 other Asian and European countries are Islamic countries. The ethnic minority culture of Henan, represented by the Hui culture, is an important resource for "the Belt and Road" initiative. It has unique cultural advantages in "the Belt and Road" consensus-driven project context. In terms of tourism development, the cultural resources of ethnic minorities in Henan Province have both significant resources and significant advantages in location and transportation. There are also a number of problems such as lack of government functions, inadequate marketing and propaganda, weak awareness of protection, and inadequate tourism product development. Therefore, we must base ourselves on the conditions of the province, the situation, and the people, do a good job of protection and inheritance in the development process, encourage and support the training of relevant professionals, improve the marketing network, and increase propaganda; highlight national characteristics and increase participation; respect differences. Strengthen communication; develop cultural commodities and build brands; strengthen the government's leading position, formulate and implement relevant development plans, grant policies, and financial support, and adopt informal measures to encourage and support the development of ethnic minority cultural tourism.
\end{abstract}

\section{The strategic opportunity of the Belt and Road Initiative}

Under the drive of the regional economic plans of the Central Plains Economic Zone and Zhengzhou Airport District, Henan Province, as the core region of the "inland open economic highland", has a prominent regional advantage in the strategy of central China's rise, and is a "one route" strategy. The important support in the pattern. At the same time, Henan Province has a population of nearly 1.4 million ethnic minorities. It ranks first in the 11 provincial-level divisions where ethnic autonomous areas have not been built, and it has 55 ethnic minorities. It also has 3 ethnic minority areas and 21 nationalities. Township (town), 863 ethnic villages. In particular, the Hui population is second only to Ningxia and Gansu, ranking third in the country, far exceeding the total of 14 scattered and mixed provinces such as Sichuan and Fujian. Since Chairman Xi Jinping put forward the concept of "all the way", more than 60 countries have actively participated in the initiative. Among them, six Central Asian countries, 20 Arab countries in the Middle East and North Africa, and 10 other Asian and European countries are Islamic countries. The Muslim population in South Asia and Southeast Asia alone exceeds 1 billion, accounting for 62\% of the total Muslim population in the world. There are many countries along the Silk Road, covering a large population, large-scale economic scale, numerous ethnic groups, diverse religious forms, and diverse ethnic cultures and religious cultures. In particular, the political instability in a number of countries and the cross-border national, religious, and sectarian conflicts will have a severe impact on the future global order and relations between big powers, and will also cause serious damage to China's rapidly expanding economic interests and political influence in the region. Impact.

As the core culture and characteristics of Islamic culture, the Hui culture absorbs and integrates 
the Han culture and other ethnic cultures into a complex culture. It has unique cultural advantages in the "One Belt and One Road" people-mindedness project context. It can be said that Hui Muslims are an important force for the construction of the "One Belt and One Road", and Hui culture is an important resource for the "One Belt and One Road" initiative. Therefore, we must protect and inherit the outstanding traditional cultures of the ethnic minorities represented by the Hui culture, and further strengthen the characteristics and laws of cultural development of ethnic minorities under the situation of in-depth development of industrialization, informatization, urbanization, marketization, and internationalization. The study has not only broken down the effective way of inheriting and carrying forward the excellent traditional culture of ethnic minorities. It not only insists on facing the modernization, facing the world, and facing the future, grasping the regularity, maintaining the nationality, embodying the times, promoting the reform and innovation of ethnic minorities culture, and continuously liberating.The important measures for developing the cultural productivity of the ethnic minorities are also the effective strategies for building and building a socialist national cultural circle with Chinese characteristics, building a national culture "Great Wall" and a cultural "bridgehead", and actively preventing and resisting the infiltration of religious culture by foreign forces.

\section{Advantages of Tourism Development of Ethnic Cultural Resources}

\subsection{Resource advantages}

Henan has 55 ethnic minorities and has a total population of more than 1.4 million people. Among them, in addition to the Hui population of 1.2 million or more, the Manchu and Mongolian people also have a large number of distributions, with populations of 100,000 and 70,000 respectively. Religious beliefs, customs, historical relics, historical sources, and lifestyles all contribute to the richness of cultural resources in ethnic minorities in Henan. The Henan Hui nationality is rooted in the cultural inheritance of the region, and it has a unique cultural value and distinctive features. It is in the Pingdingshan Majiataer Mongolian Customs Park and then in the Gaoshan Immigrant Village in Dengzhou City.

\subsubsection{Cultural relics}

There are three mosques in Henan Province that belong to state-level key cultural relics protection units and many provincial and municipal key cultural relics protection units. For example, Kaifeng Dongda Temple, known as the "Henan First Square," is a simple and elegant building. It is a model of the combination of Chinese traditional culture and Islamic culture. Its rich cultural connotation and glorious history are also admirable. Another example is the Wangjia Hutong Muslim female school, which was first established during the Jiaqing period of the Qing Dynasty and was the first to open the temple of the Muslims. It has become one of the landmark events in the process of localization of Islam in China. It has also become the province's famous Hui scholar Shui Jingjun and the United Kingdom. Scholar Maria Jasok's "History of the Temple of the Muslims" was renowned overseas and sparked the attention of scholars both at home and abroad. As the earliest halal female temple in our country's existing history, it has many important values.

\subsubsection{Style and Art}

The Hui nationality costumes and dance music designed by Henan Province in 1995 first appeared in the National Minority Traditional Sports Association, which caused widespread concern and high praise. Kaifeng Hui Traditional Sports Performance Group performed the boxing, boxing, boxing, wrestling, stone lock, and other projects, has repeatedly boarded television stations at all levels. Traditional sports items such as stone locks and dance items Wenshi Dance, Hui Yangge, etc., have been included in the national intangible cultural heritage list.

\subsubsection{Ethnic customs}

Henan Minorities are located in the Central Plains and are deeply influenced by regional culture. They have distinctive local ethnic characteristics, and their scarcity, uniqueness and importance 
have created tremendous social and economic value and development potential. Taking the "Ma Bao Ta Er Mongolian Culture and Culture Garden” project in Jingdu Village, Beidu Town, Zhanhe District, Pingdingshan City as an example, its investment scale reaches more than 20 million, and the estimated annual income is 2 million yuan. According to textual research, Ma Baota was born in the Mongolian aristocratic family and was given the service of the three generals, Yong Yong Dajun, the regular scriptorate, the Privy Council, and the light bus. For the first nine years (1349), he was honored as Fan Yang Junhou. The Matu Ta'er Tomb is the most complete and largest Mongolian aristocrat tomb in the Central Plains. Tombstone, Huabiao, and Shinto in the Yuan Dynasty are still present. Tombstone calligraphy is strong and powerful. It is rare in Henan Province and rare in the country. It has high artistic and cultural value.

\subsubsection{Ethnic Street Blocks}

In Kaifeng, Zhengzhou, and Luoyang, there are a large number of neighborhoods inhabited by Hui people. These ethnic communities, usually centered on mosques, constitute a spatial unit with unique cultural tastes. Take Dongdaisi Community in Kaifeng as an example. The surrounding communities of the mosque live in more than 2,000 households with more than 7,000 Hui residents. Besides the mosques, there are the first Hui middle school, the first Hui primary school, and the first Hui nationality kindergarten in Henan Province. The local Hui people live around the temple, and their daily lives such as weddings, funerals, slaughter, slaughter, and religious activities are closely related to the mosque. This special living pattern and way of life gave birth to its unique national culture, and it also enabled people to observe the entire culture of the Central Plains Hui culture from a city community.

\subsection{Market advantages}

Henan is located in the center of the Greater Zhongyuan area where China has the most densely populated and largest economic aggregates, and has the most advanced culture and education. Henan's ethnic minority cultural resources clustering area is also distributed in small cities and towns around the central city, such as Zhoukou Huiguan Town of Huaiyang, and Jixian Zhuxian Town of Kaifeng. Located 22 kilometers south of Kaifeng, Zhuxian Town is one of the four famous towns in the country. During the Ming and Qing Dynasties, a large number of Chinese and foreign Muslim merchants, represented by the Sai Family (descendants of the Arabs) and Shaanxi "Ma Ke", stepped into this commercial center and built seven mosques, including Dongsi, Beisi, and Temple. Among them, the Beibei Temple was established in the Jiajing Decade (1531) and rebuilt in the nine years (1744) of the Qing Emperor Qianlong. It has a history of more than 470 years. Relevant leaders of the provincial government have personally visited and inspected and organized more than a dozen provincial officials of the provincial direct bureau to hold an on-site meeting in Zhuxian Town, requesting in-depth excavation, development, integration, and innovation of existing historical and cultural relics and cultural elements. Unique geographical location, convenient and fast traffic conditions, and unique cultural resource advantages constitute the great potential of these ethnic minority cultural resource which connect the primary and secondary markets.

\section{The Significance of Tourism Development of Ethnic Cultural Resources in Henan Province}

\subsection{Contributing to the inheritance and development of ethnic minority cultures}

The development of cultural resources for ethnic minorities can facilitate the exchange of ethnic minority cultures. Under the current social development situation, it is impossible to demand that the younger generation of ethnic minorities be as happy as their fathers and be willing to freely learn and inherit the excellent national culture. In fact, many young people in ethnic minorities generally do not choose to learn the national culture at home and use it as their profession. The development of cultural resources of ethnic minorities has created a good opportunity and conditions for their inheritance. The younger generation can obtain effective employment opportunities without having to leave their hometowns, have a relatively stable income for work, 
and fundamentally solve the problem of inheritance of outstanding ethnic minorities. Dilemma. At the same time, the promotion of local economic and social development by minority cultural tourism also enables local government finances to devote more resources to help the development of ethnic minority cultural industries.

\subsection{Promoting local economic and social development in areas inhabited by ethnic minorities}

Accelerating economic and social development in ethnic minorities and ethnic regions is an important part of the construction of the Central Plains Economic Zone, and it is related to national unity and social stability. In the past 40 years of reform and opening up, there have been historical and dramatic changes in the economic and social status of ethnic minorities and ethnic groups living in Henan Province. However, due to factors such as historical and natural conditions, there is still a certain gap between the production, living, and income levels of some ethnic minorities, especially rural ethnic minorities, and the average level of the province. Exploring and making full use of the unique advantages of ethnic minority cultures has become an important choice for accelerating the development of ethnic minorities and ethnically populated areas.

\subsection{Contributing to the transformation of great provinces of cultural resources into strong provinces of culture}

As a major province of cultural resources, Henan has made great progress in the process of advancing to a strong cultural province. The cultural industry in the province has continued to grow and develop, and its role in promoting the national economy has become increasingly evident. Under this situation, cultural resources of ethnic minorities are an important part of the treasure house of Henan's cultural resources and deserve to do well. The design and development of cultural tourism for ethnic minorities will certainly add new and powerful impetus to this process.

\section{Problems in Cultural Development of Ethnic Minorities in Henan Province}

Although Henan has a rich and unique cultural resources for ethnic minorities, there are factors that restrict the development of cultural tourism in ethnic minorities in Henan in areas such as system, planning, capital, operation, awareness of innovation, supporting facilities, and quality of employees.

\subsection{The government planning and guidance functions need to be strengthened}

While formulating and revising plans for local tourism development, all levels of tourism administrations in Henan shall pay attention to or enrich the content of tourism cultural development, speed up the transformation of government functions, rationalize the management system of cultural tourism, and promote the gradual realization of government administrative departments. The transition from management to management has shifted from micro-management to macro-control, gradually changing the government into a service.

\subsection{Insufficient marketing and promotional efforts}

The lack of sufficient funds and intensity in propaganda for cultural resources of ethnic minorities in Henan has resulted in a lack of a favorable development environment for the cultural tourism industry. Provincial Tourism Information Network and other official portals do not have relevant sections or content. At the same time, it is difficult to retrieve relevant information such as routes, fares, catering, accommodation, etc., which objectively reduces tourists' expectations and wishes. The root cause is the immaturity of the market.

\subsection{Minorities in cultural protection of ethnic minorities}

In the process of developing ethnic minority cultures, due to limitations in understanding, or out of consideration of interests, human damage and constructive destruction are more prominent. Ethnic minority cultures are formed through long-term accumulation in specific historical and cultural contexts. They have a specific historical and cultural space and undermine the original 
nature of ethnic minority cultural heritage. Cultural heritage is also likely to lose its cultural value. Moreover, in the process of social development, especially in the process of development and utilization, the culture of ethnic minorities is also inevitably confronted with the test of carrying capacity and the impact and challenges of heterogeneous culture.

\subsection{Insufficient development of cultural tourism products for ethnic minorities}

In order to maintain necessary livelihoods and production, all ethnic groups have formed "ethnic minorities culturally distinctive products" with specific uses, specifications and styles, and enriching their culture. Because most of them have distinctive national characteristics and unique cultural charm, they are widely welcomed by the market and have broad prospects. However, at present, the development of ethnic minorities with cultural characteristics in Henan has not yet formed a healthy situation. The development and research forces are weak, and the effective supply of the market is insufficient. The potential customer groups have yet to be developed.

\section{Strategies for Accelerating the Design and Development of Ethnic Cultural Tourism Has a large team of coaches.}

To truly achieve the effective transmission and sustainable development of ethnic minority cultural resources, we must base ourselves on the province's situation, people's conditions, and local conditions, fully learn advanced experience, and seek scientific and rational development strategies and realistic paths. In light of the actual situation in Henan, in the process of tourism development of ethnic minority cultural resources, we should consider starting from the following aspects:

\subsection{Safeguard and inherit the ethnic cultural tourism development}

Many of the ethnic minority cultures are non-renewable resources that can be destroyed or even destroyed if they are not protected. Therefore, we must scientifically and reasonably develop and protect minority culture. On the one hand, we must establish the awareness of protecting the cultural resources of ethnic minorities and start from the direction of mutual complementarity between Han and ethnic minorities. Even if the Han people attach great importance to it, we must also enable ethnic minorities to dialectically treat their traditional way of life and cherish their uniqueness. Cultural Value. On the other hand, from the policy level, it is necessary to strengthen the inheritance and development of ethnic minority cultures, especially the national customs, festivals, dances, operas, and cultural relics that are on the verge of disappearing.

\subsection{Train ethnic minority cultural tourism talents}

The first is to develop professionals who develop ethnic minority cultural tourism. They have the ideological and theoretical qualities necessary to carry out this work, and they must master the methods and skills of conservation, development, and rational use to ensure that the most appropriate methods and skills are used. Complete this work. The second is to set relevant professional orientations in colleges and universities to cultivate the various types and levels of talents for ethnic minority heritage, protection, development, management, and research.

\subsection{Improve marketing network and increase propaganda}

Make full use of modern marketing methods, mobilize all available media, and spare no effort to promote ethnic minority culture. While giving full play to the role of traditional media, we must also integrate with modern science and technology, make use of modern media such as the Internet, and make rational use of various resources to increase the visibility of ethnic minority cultural tourism projects, establish an image of the industry, provide service information, and win tourists' approval.

\subsection{Highlight the cultural features of ethnic minorities and enhance the participation of tourists}

In the process of developing cultural tourism for ethnic minorities, we must pay attention to the 
characteristics of ethnic groups. If conditions permit, they should also provide opportunities for tourists to participate in the event personally, to experience different ethnic customs, to appreciate unique cultural connotations, to appreciate the cultural charm behind them, to meet their psychological needs, and to help them further understand the relevant national culture. Connotation.

\subsection{Respect ethnic cultural differences and increase exchanges}

The cultural differences among various ethnic groups are precisely the fundamentals that distinguish them from other nations and maintain their own unique values. However, everything has a two-sided nature. The stronger the ethnic differences, the more difficult it is to gather ethnic minority cultures and the more likely conflicts among ethnic groups occur. Therefore, it is necessary to have a sufficient understanding of the differences between various ethnic cultures. On this basis, we must respect differences, increase exchanges, and promote the common prosperity of all ethnic cultures.

\subsection{Develop cultural products and create brand cultural rroducts}

Every ethnic group maintains a necessary lifestyle and will form material and spiritual products that have specific uses, specifications and styles, and enrich the culture of the nation. The cultural market for ethnic minorities has broad prospects. Its distinctive national characteristics constitute a powerful competitive advantage. We attach great importance to and take effective measures to promote the design and development of cultural products for ethnic minorities and incorporate them into the overall planning for tourism development. At the same time, we will try our best to create one or several brands and create a brand effect, which will not only be beneficial to the protection and inheritance of minority cultures. It also helps to attract investment, develop markets, explore its economic potential, and then form a simultaneous development of economy and culture.

\subsection{The government must strengthen its dominant position in the development of ethnic minority cultural tourism}

The lack of government, policies, and institutions in the process of tourism development of ethnic minority cultural resources has always been an important factor hampering their development practices. Based on the dual attributes of political and economic influence of ethnic minority cultural resources, priority should be given to government-led model. The government should promptly follow up the introduction of relevant policies to guide and assist the development of ethnic minority cultural brigades, including establishing specialized research institutions to provide policy consultation and intellectual support, formulating and implementing development plans, encouraging and supporting specialized personnel training, and giving relevant industrial policies and financial support, etc., informally based on reality, adopt comprehensive measures to encourage and support the development of ethnic minority cultural tourism.

\section{Acknowledgement}

This is science and Technology Development of Henan Provence Soft Science Research Program Achievement in 2018. Project Number: 182400410393.

\section{References}

[1] Yuan Siming, Li Xiaobiao. Promoting the Development of Ethnic Minority Culture in Henan Province[J]. National Forum, 2014(02):26-30.

[2] Li Qiang. Suggestions on the Protection and Development of Henan's Ethnic Traditional Culture [J]. Modern Business Industry, 2015, 36(08): 43-44.

[3] Liu Fang. On the Development Strategy of Henan Province's Cultural Tourism Industry [M]. Chinese Business, 2011, (6).

[4] Li Xiuzhi. Exploration of the "Tourism Province" Development Strategy in Henan Province [J]. 
Journal of Luoyang Teachers College, 2009, (8).

[5] Li Yaqing. On the Selection of Tourism Projects Developed in Zhuxian Town[J]. Journal of Kaifeng Institute of Education,2003, (12). 